\title{
Development technique for deep drawing without blank holder to produce circular cup of brass alloy
}

\author{
Ali Hassan Saleh ${ }^{1}$, Ammer Khalaf Ali $^{2}$ \\ ${ }^{1}$ Institute of Technology/ Baghdad, Iraq \\ ${ }^{2}$ Technical College/ Baghdad, Iraq \\ *Corresponding author E-mail: ali_aljibury1956@yahoo.com
}

Copyright $\odot 2015$ Ali Hassan Saleh, Ammer Khalaf Ali. This is an open access article distributed under the Creative Commons Attribution License, which permits unrestricted use, distribution, and reproduction in any medium, provided the original work is properly cited.

\begin{abstract}
In this paper a new mechanism for deep drawing was proposed to produce circular cup from thin plate without blank holder. In this technique the die assembly includes punch, die and die-punch. A 2D axisymmetric finite element model was built using DEFORM software. Effect of die geometry (half- cone angle) on maximum load, thickness distribution, strain distribution and effect of clearance ratio between punch and (die-punch) on the wrinkling of the cup were investigated. Three half-cone angles of die (15o, 30o and 45o) were used for forming sheet metal of brass (CuZn37) which had initial thickness of $(1 \mathrm{~mm})$ at four clearance ratio $(\mathrm{c} / \mathrm{t})$ for die of $30 \mathrm{o}$ half-cone angle. Finite element model results showed good agreement with experimental results. Die of $30 \mathrm{o}$ half-cone angle with clearance ratio (c/t) of 0.9 gave the best product without wrinkling. The main advantage of this technique compared to the conventional deep drawing is that the circular cup can be carried out in single action press with limit drawing ratio (LDR) of 1.86 and blank diameter to blank thickness ratio $(\mathrm{d} / \mathrm{t})<86$.
\end{abstract}

Keywords: Sheet Metal Forming; Deep Drawing; FEM; LDR

\section{Introduction}

In deep drawing a flat sheet-metal blank is formed into a cylindrical or box-shaped part by mean of a punch that presses the blank into the die cavity. Deep drawing may be carried out without a blank holder provided that the sheet metal is relatively thick to prevent wrinkling [1]. Recently many researchers interested in deep drawing without a blank holder process such as conical and tractrix dies for relatively thin sheet.

Hassab-Allah [2] used conical die without blankholder to produce circular cup. He investigated the ratio of blank diameter to blank thickness $(\mathrm{d} / \mathrm{t})$ that the flange resistance to buckling and wrinkling when this ratio gets sufficient to eliminate the need of blankholder. He mentioned that this ratio can be defined by the value of $d / t<50$. He also concluded that, in cases of drawing with $20 \%$ simultaneous ironing ratio LDR of soft aluminum using a rough punch was increased to 2.77 compared to 2.5 in the case of drawing without ironing. Hassab-Allah et al [3] Proposed a novel forming technique for drawing square cups in which a circular

Blank is drawn without a blank holder through a conical die. They used

FEM to study this process and concluded that the high values of limiting drawing ratios LDR's were obtained. They also concluded that the material flow between the straight walls and the corners of the deformed part was found to be improved. Hezam et al [4] used finite element simulation to investigate the developed setup in order to determine the optimum die cone angle. Also the effects of the original blank thickness and the orientation of the blank rolling direction to the punch side on the limiting drawing ratio (LDR) and punch load are experimentally investigated. They concluded that the half cone angle of $18^{\circ}$ showed the best drawability for the new technique. The LDR is significantly higher than that obtained by conventional technique. Hassab -Allah, [5] designed a new technique of deep drawing without blank holder for manufacturing square cups by drawing circular blanks of relatively thin sheet metal through conical die. He investigated the effect of many parameters on limit drawing ratio (LDR) in this process and concluded 
that the LDR improved with the proposed new technique. Dhaiban, et al [6] introducd a new technique for deep drawing of elliptic cups through a conical die without blank holder or draw beads. They built 3D parametric finite element model. They studied the effect of die, punch geometry, die aperture length and punch fillet radius on limiting drawing ratio (LDR), drawing load and thickness strain of the cup. They used seven punches; die of aspect ratio equal to (2) and blank of brass with initial thicknesses of 1.5, 1.9, 2.4 and $3 \mathrm{~mm}$ at different clearance ratios (c/t). They obtained limiting drawing ratio of (2.28). Kumar [7] used furui's conical cup test to determine the diametrical ratio for different materials. This is used as measure of the formability index in this test. So formability is expressed as diametrical ratio. Comparing the values of diametrical ratio of three materials, the diametrical ratio is small in catridge brass .So this material has better formability nature. These test results are sensitive to thickness of sheet metal and punch diameter. The process carried out without help of blank holder. FEM is a powerful tool to simulate metal forming processes and prediction of their parametars [8], [9].

In this study a new technique was proposed for deep drawing process to produce circular cup from thin plate without blankholder. Finite element analysis was used to investigate the effect of cone die angle and clearance ratio on the parameters of this process.

\section{Finite element model}

In the modeling of the deep-drawing process many complex problems were encountered due to non-linearity, the presence of elasto-plastic transformations and the non-constant boundary conditions of contact with friction. Proper selection of element type, element size and modeling variables is crucial to the validity of the model [6].

In the present work, DEFORM 2D V10 software was used for simulating the deep drawing process. An axisymmetric model 2D was used.

\subsection{Meshing}

Selection of an appropriate element type in FEM is essential for obtaining reliable analysis results. Mesh density of the blank and tools affect the accuracy of the results. The element type selected for meshing the workpiece is a high order, 8 -node 2D rectangular element $0.16 \mathrm{~mm}$ edge length was found to be appropriate. The die and punch were assumed as rigid body, their surfaces were defined as non-deformable by using rigid lines surrounding their representative areas, while the workpiece is assumed as deformable body.

\subsection{Creation of contact elements}

The contact type used in this study for die-workpiece, punch-workpiece and (die-punch)-workpiece interfaces is rigid to flexible and surface to surface contact for represent contact and sliding between the surfaces of tool set and workpiece.

\subsection{Boundary condition}

For simplifying the simulation of the deep drawing processes, the finite element model of the sheet material and tool (punch, die and die-punch) the following assumptions were made: temperature of blank remained constant, no heat transfers between workpiece and tool set, the dies were rigid, the upper die (die-punch) moved along the y-axis at a constant speed $(10 \mathrm{~mm} / \mathrm{min})$ and the lower die (cavity) was stationary during the forming process. The circular blank was fixed along the center line of the billet moving on the $\mathrm{x}$-axis direction as shown in fig.(1).

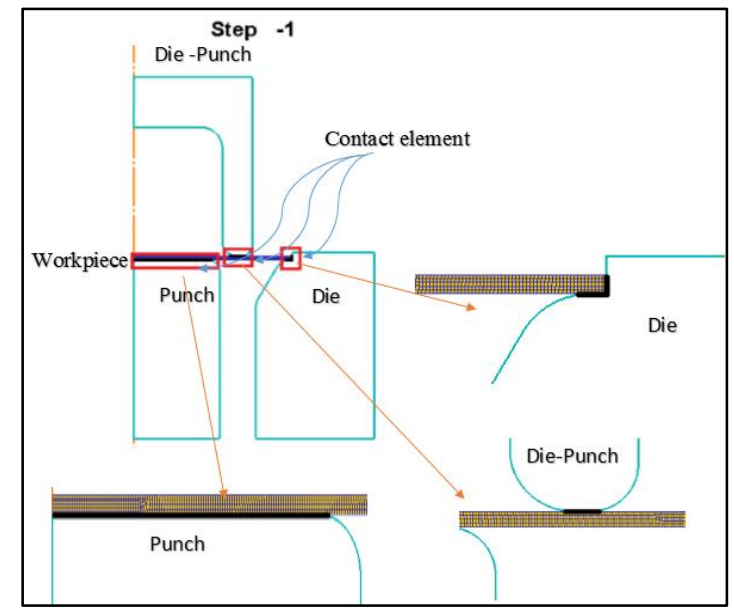

Fig. 1: Model of Deep Drawing Operation without Blank Holder 
In DEFORM software; a load is applied in increments with a certain number of steps. A bout 100 steps were used to obtain accurate results by performed a convergence analysis.

\subsection{Friction coefficient}

Friction coefficient may depend on the type of the materials in contact and surface roughness. In this study, the friction coefficient was taken constant as $(\mu=0.11)$ in dry condition between punch, (die- punch), die and blank.

\subsection{Material properties}

To simulate deep drawing without blank holder, the condition of non-linear, isotropic and constant temperature (room temp.) were adopted. Material properties of copper alloy used were $\left(\sigma_{\mathrm{Y}}, \mathrm{E}, \rho\right.$ and $\left.v\right)$ and their values were taken from DEFORM 2D library which coincide with the values that obtained in experimental procedure.

\subsection{Forming cup as a product}

The simulation carried out of deep drawing without blank holder is to produce a cup with dimension as shown in fig. (2).

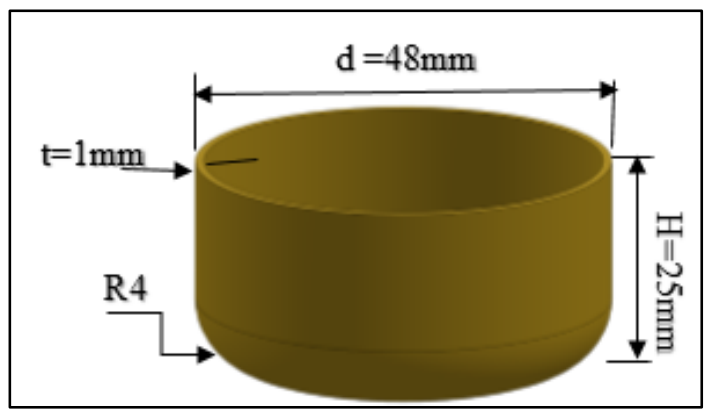

Fig. 2: Geometry of Final Product

\section{Experimental procedure}

\subsection{Material of the blanck}

Copper alloy $(\mathrm{CuZn37)}$ which is the major brass alloy for cold forming process was selected in this work to carry out the experimental tests.

\subsection{Blank preparation}

Blanks used in experimental tests were cut from sheet of thickness 1mm with dimensions of (100x100mm) (as a square shape). Then, to eliminate the work hardening at the rim of blank caused by cutting, the squares were turned to make circular blanks with a diameter of $(86 \mathrm{~mm})$.

\subsection{Mechanical properties of the material}

Tensile test was carried out to determine the mechanical properties of the material of blank as shown in table (1).

Table 1: Mechanical Properties of Brass ( $\mathrm{Cu} \mathrm{Zn} 37)$.

\begin{tabular}{llllll}
\hline Property & Yield point $(\mathrm{MPa})$ & Tensile strength $(\mathrm{MPa})$ & Young's modulus, E (GPa) & Poisson's ratio, $v$ & Elongation A50\% \\
\hline Nominal* & $\leq 180$ & $300-370$ & 110 & 0.35 & $\geq 38$ \\
Actual $* *^{151.75}$ & 361.333 & 110 & 0.35 & 41.075 \\
\hline
\end{tabular}

*: Source ASM volume 22005 Handbook.

**: Tested by (Tenius Olsen) tension test device in CENTRAL ORGANIZATION

For Standardization and Quality Control 


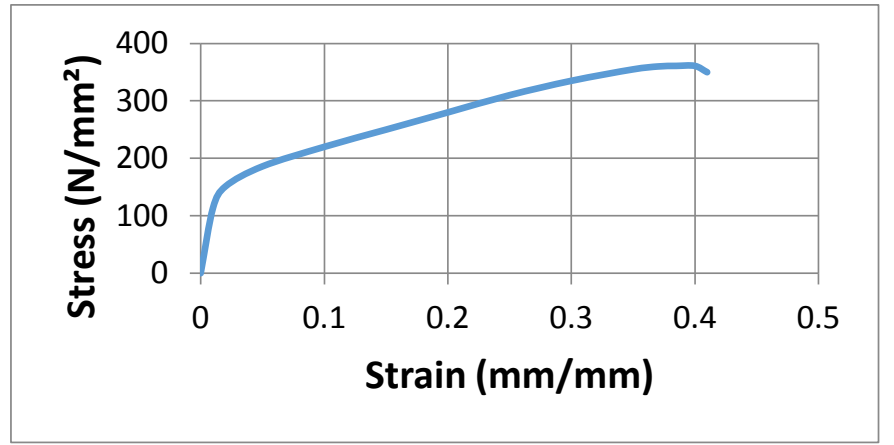

Fig. 3: True Stress-True Strain Curve.

\subsection{Ring compression test}

To determine coefficient of friction, ring compression test was used. The value of friction coefficient obtained from this test as a range of three tests was (0.11) also this value employed in the simulation procedure.

\subsection{Deep drawing rig without blank holder}

Fig (4-a) illustrates the rig of deep drawing without blank holder. It contains die, punch and die-punch. Three dies have half conical angle of $\left(15^{\circ}, 30^{\circ}\right.$ and $\left.45^{\circ}\right)$ with radius $R_{1}=4 \mathrm{~mm}$ and $R_{2}=5 \mathrm{~mm}$ were used as shown in fig. (2-b). Three punches and three (die-punches) were used to get four clearance ratio (c/t) $((1.15,1.05,1$, and 0.9$)$, the punch had corner radius of $5 \mathrm{~mm}$ as shown in fig. (2-c). The punch fixed into the die and die-punch presses the blank inside the die and around the punch.

\subsection{Preparation of blank for deep drawing test}

Blank of diameter $(86 \mathrm{~mm})$ was prepared from sheet of copper-zinc alloy with thickness of (1mm). The blank cut from sheet using press cutting machine as a square blank of dimensions $(100 \mathrm{x} 100 \mathrm{~mm})$. Then it was machined on a turning machine to a circular shape of diameter $(86 \mathrm{~mm})$ to eliminate the stress concentration on the end of blank which might occur through the cutting on press.

a

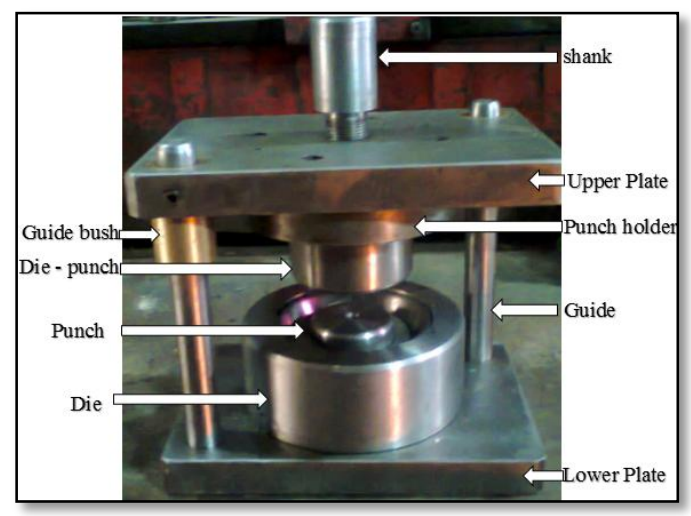

b

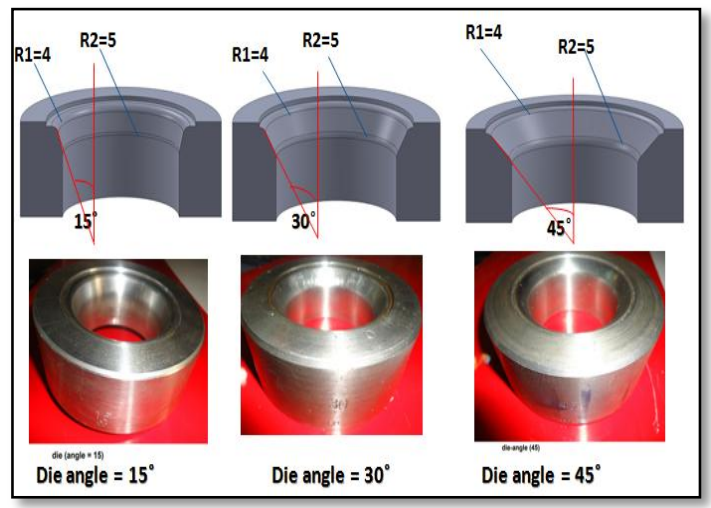

$\mathrm{c}$

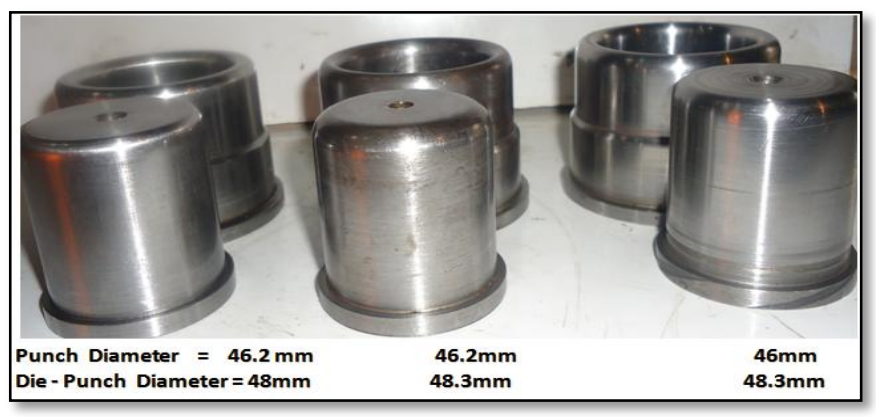

Fig. 4: A) Assembly of Rig B) Dies Geometry C) Punches and(Die-Punches) 


\subsection{Testing machine}

Computerized universal testing machine type(United Test)of 300KN capacity was used to carry out the tests of deep drawing without blank holder as shown in fig.(5).

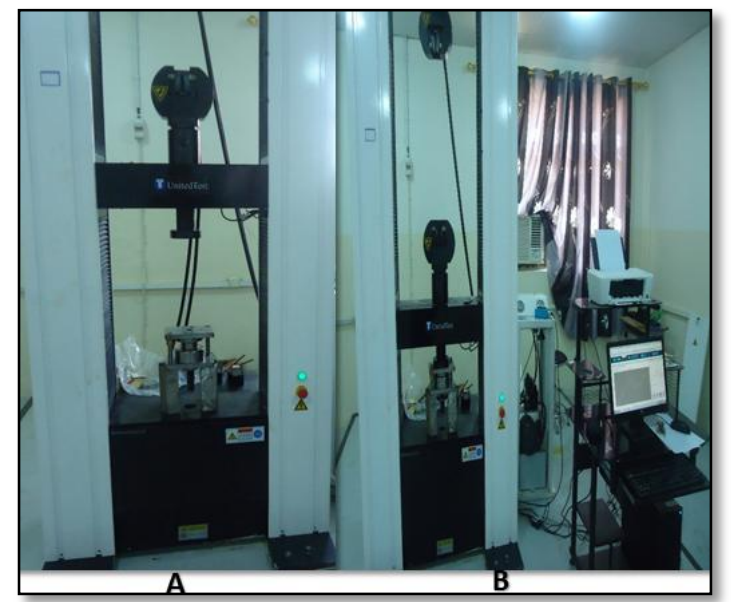

Fig. 5: A) Before Pressing \& B) after Pressing Operation.

\subsection{Thickness's strain measurement}

In order to study the thickness strain distribution within the cup during drawing operation, a grid pattern of $2 \mathrm{~mm}$ square, was printed on undeformed blanks, by using mechanical grid marker as shown in Figure (6-a). In order to measure the cup wall thickness, the successfully drawn cup was divided into two parts by using a diamond saw as shown in Figure (6-b). Digital thickness micrometer was used to measure the cup wall thickness and the changes in the grid square during the deformation. Cup thickness and the length of distorted grid radius were measured along the lines.
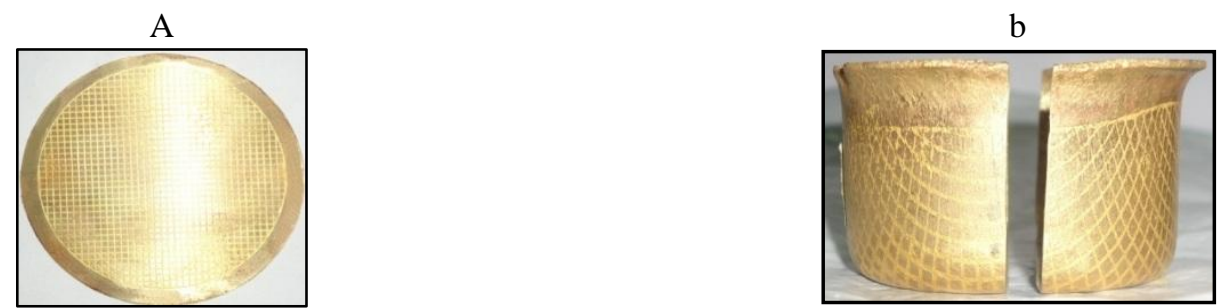

Fig. 6: A) grid square on the blank, B) Sample of forming grid cap

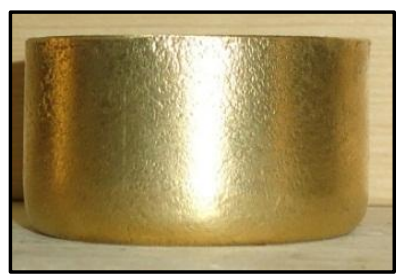

Fig. 7: Samples of Drawen Cups b

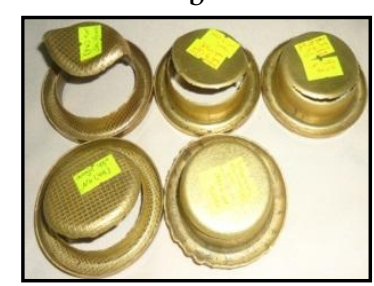

C

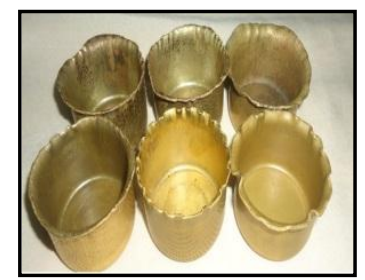

$\mathrm{d}$

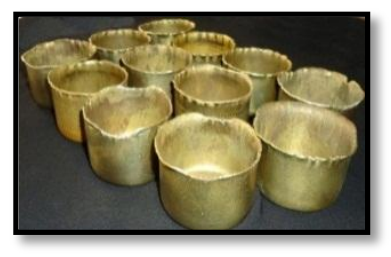

\section{Results and discussion}

The main result obtained in this study is the production of circular cup from thin plate (1mm thickness) without blankholder, successfully at limiting drawing ratio (LDR) 1.86. Also the ratio of blank diameter to blank thickness (d/t) obtained through design of rig in this study was $\mathrm{d} / \mathrm{t}<86$.

\subsection{Effect of die angle on the drawing load}

Fig (8) illustrates the relationship between drawing force (Die-punch load) and displacement. This relationship shows a good agreement between theoretical and experimental values. It is observed that maximum drawing force at angle $45^{\circ}$ and minimum drawing force at angle $15^{\circ}$ but causes wrinkling in cup rim. The value of maximum force at angle $30^{\circ}$ is 
between the above two angles, but earing observed on the product. This defect can be eliminated with optimization of the blank to obtain a cup with uniform height. It can be saied that the peak drawing force increases with the increasing of die half cone angle [6].

It is also observed that the large cone angle of die $\left(45^{\circ}\right)$ causes fracture of cup before the completion of the drawing stroke. This is because the high friction between die and blank due to the increase of surface area. The variation between the maximum draw force and minimum draw force is about $25.32 \%$.

\subsection{Wall thickness distribution}

The thickness is usually constant under the punch base, and then increases on the cup wall until it reaches maximum value at the end of wall. The best distribution of wall thickness in this process was obtained with the die of cone angle $30^{\circ}$ as shown in fig.(9). This is because of good drawability that occurs at this angle of die which lead to more homogeneity of wall thickness also for another reason which is no wrinkling occurs at this cone angle of die. Because of a suitable radius of punch, less thinning in the cup was observed at this region.
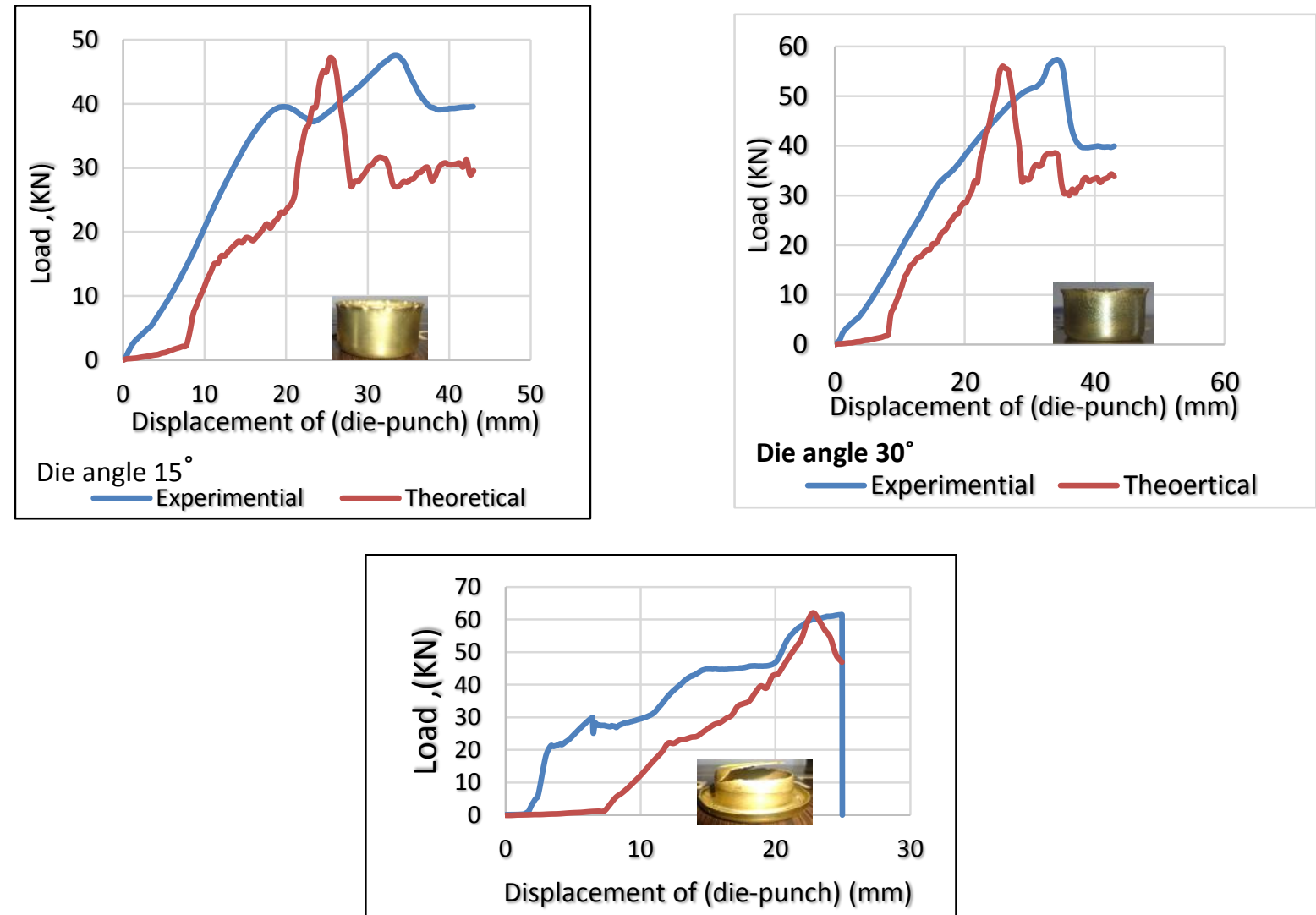

Die angle $45^{\circ}$

Experimential Theoretical

Fig. 8: Load Displacement Relationship of (Die-Punch) for Three Cases

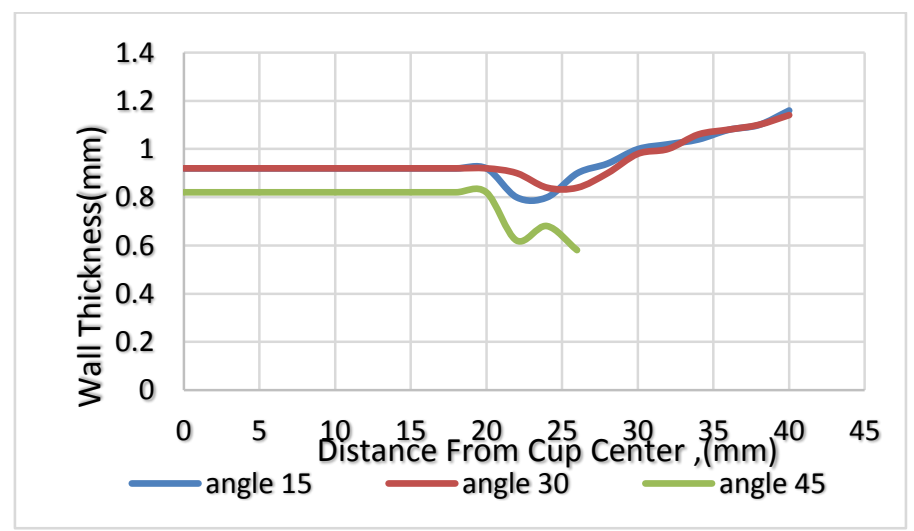

Fig. 9: Experimentally Wall Thickness Distribution of the Cup 


\subsection{Thickness strain distribution}

Thickness strain behavior of material for each angle of die is illustrated in fig (10). There is similarity in behavior of this strain for two angles $\left(15^{\circ} \& 30^{\circ}\right)$. Thickness strain $\left(\varepsilon_{t}\right)$ starts to change at the punch profile radius and has a negative value due to stretching, and then an increase occurs because of circumferential compressive stress to reach a maximum value at the cup rim. From above fig. the results show that, thickness strain in die of cone angle $30^{\circ}$ is the best and the finite element model shows a good agreement with experimental results.
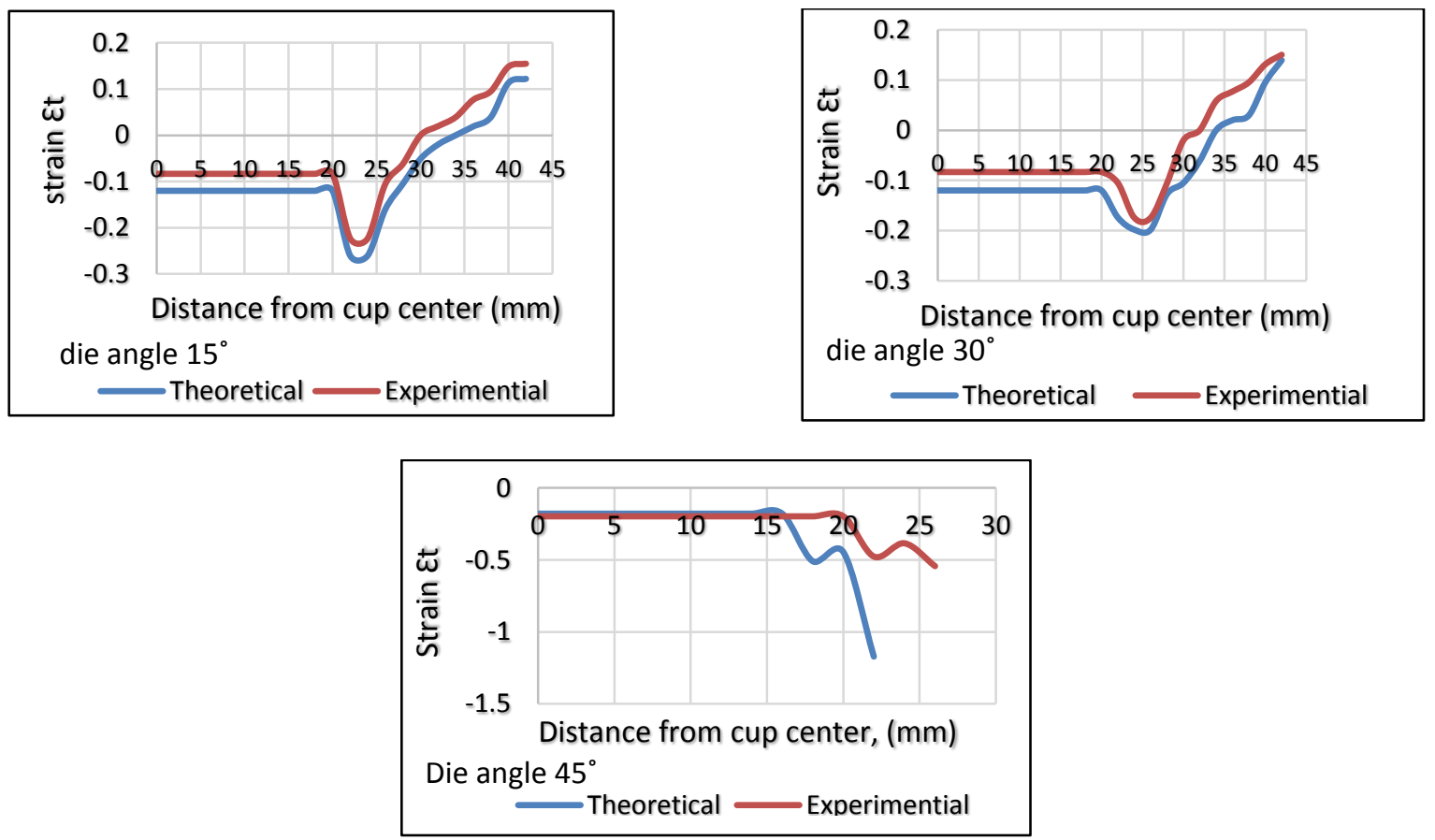

Fig. 10: Distribution of thickness strain for three cases

\subsection{Effect of clearance ratio $(\mathrm{c} / \mathrm{t})$}

Four clearance ratios (c/t) were selected $(1.15,1.05,1$ and 0.9$)$, which represents the clearance between punch and (diepunch) for die of cone angle $30^{\circ}$. It was found that, the drawing process was completed but buckling and wrinkling in the cup wall, happened when using high clearance ratio, c/t $(1.15,1.05 \& 1)$ but clearance ratio c/t $(0.9)$, gave the best product which is deeper and has no surface irregularities. The disadvantage of lowering clearance ratio is the production of high ears. Earing defect can be overcome through optimization of blank to obtain uniform height of cup. Table (2) shows photographic picture of successful and failured drawing of circular cups. The clearance ratio has a large effect on the (die- punch) load as shown in fig.(11). It can be also noticed that the die-punch load before circular aperture (during the cupping stage) was not affected by clearance ratio. Maximum die-punch load increases with the decreasing of clearance ratio because of increasing in friction between and (die-punch) [6].

Table 2: Products According To Clearance Ratio (C/T)

\begin{tabular}{lllll}
\hline Clearance Ratio & 1.15 & 1.05 & 1 & 0.9 \\
Product & & & &
\end{tabular}




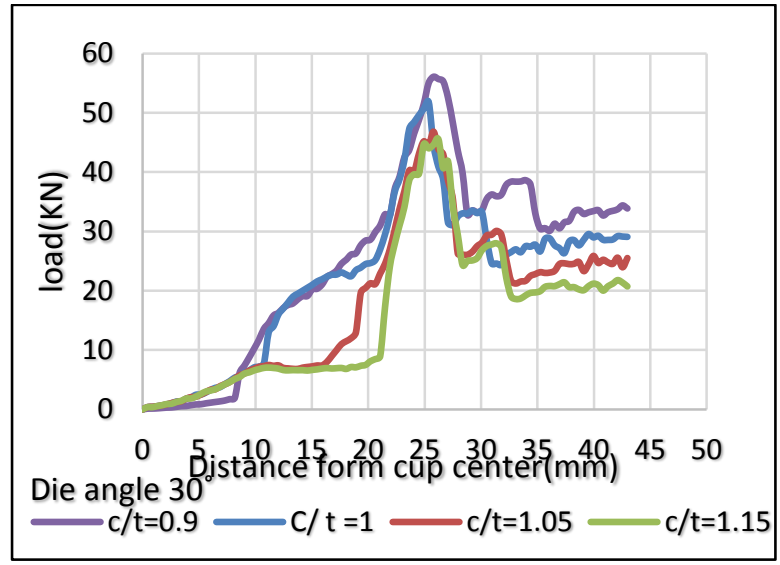

Fig. 11: Drawing Load Clearance Ratio Relationship

\subsection{Stress distribution on the product}

Stress distribution on cup wall for different angles of dies with constant clearance ratio (0.9) obtained from DEFORM software is shown in fig.(12). The value of effective stress appeared at the punch base remained constant because there is no forming occurred under this region. The max. Effective stress appeared at radius of cup for all dies and its value for die of $15^{\circ}$ cone angle less than other dies but wrinkling appeared clearly on the product while max. Effective stress for die of angle $30^{\circ}$ greater due to improvement of drawability that cup deeper and without wrinkling. The higher value of max. Effective stress appeared with die of angle 45 because of high friction and difficulty of drawability the lead to fracture the product.

a) (Die angle $15^{\circ}$ )

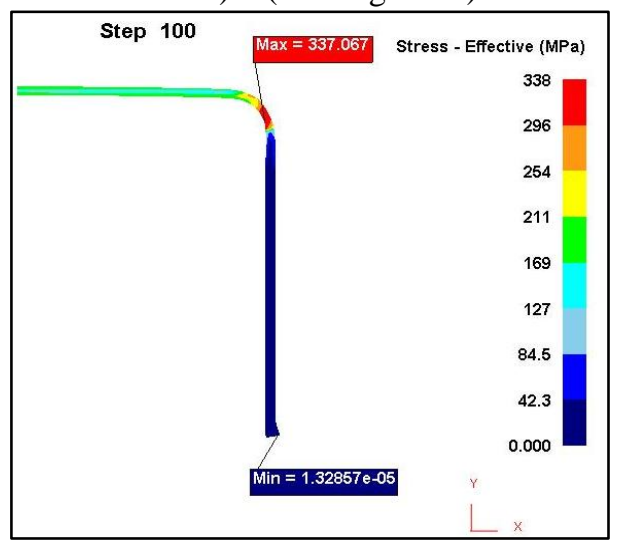

b) (Die angle $\left.30^{\circ}\right)$

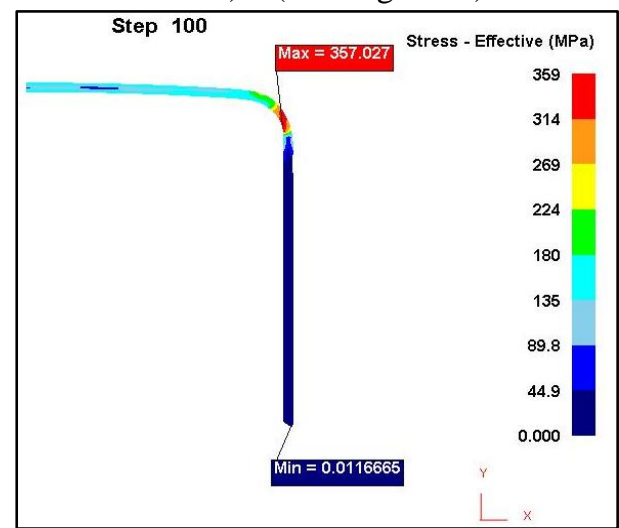

(Die angle $\left.45^{\circ}\right)$

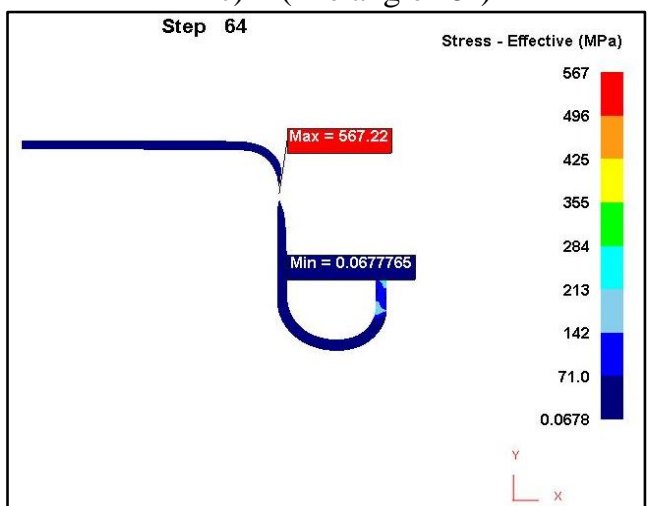

Fig. 12: Stress Distribution on the Product ( Cup) According to Die Cone Angle

\section{Conclusions}

The conclusions of this paper can be summarized as follows:

1) A new technique is introduced in this paper for producing circular cup from thin blank (1mm thickness) using tooling set without blank-holder. 
2) A die with half cone angle $30^{\circ}$ and clearance ratio of (c/t) 0.9 between punch and (die-punch) has shown the best drawability for the new technique and product without wrinkling but has earing.

3) The wall thickness and thickness strain distribution occur with die of cone angle $30^{\circ}$ and clearance ratio (c/t) 0.9 .

4) The value of max. Effective stress distribution increases as die cone angle increases, too. But the die of cone angle $30^{\circ}$ produced cup successfully without wrinkling.

5) The limiting drawing ratio (LDR) obtained in this process is 1.86.

6) The numerical results for maximum load were in a good agreement with experimental results.

\section{Acknowledgement}

The authors are grateful to Mr. Ahmmed Jassim Hassan of technical college/Baghdad for help with the idea and experimental procedure of this work.

\section{References}

[1] Serope Kalpakjian " Manufacturing Processes For Engineering MaMaterial by Addition-Wesley Publishing Company 19 19 1984. " Copyright

[2] Hasab-Alla I. M.," A Finite Element Simulation and Experimental Verification of the Deep Drawing of Sheet Metals Without Blankholder With Simultaneous Corrective Ironing", Ph.D thesis, Assiut university, Egypt,(1993).

[3] I. M. Hassab-Allah, L. M. A. Hezam, and M. G. El-Sebaie," A Novel Forming Technology For Drawing Square Cups" International Conference on Production Engineering \& Design For Development, PEDD7, Cairo, February 7 - 9,(2006).

[4] L.M.A.Hezam, M.A.Hassan, I.M.Hassab-Allah, M.G.El-Sebaie," Development of a New Process For Producing Deep Square Cups Through Conical Dies" International Journal of Machine Tools \& Manufacture, 49, 773-780, (2009). http://dx.doi.org/10.1016/j.ijmachtools.2009.04.001.

[5] Hassab -Allah, I. M.," Finite Element Simulation of Square Cup Drawing Through a Conical Die " Fourth Assiut University Int. Conf. on Mech. Eng. Advanced Tech. For Indus.

[6] Prod., December 12-14 (2006).

[7] Abdullah A. Dhaiban, M.-Emad S. Soliman, M.G. El-Sebaie," Finite Element Modeling and Experimental Results of Brass Elliptic Cups Using a New Deep Drawing Process Through Conical dies" Journal of Materials Processing Technology ; 214, 4; 828-838, (2014). http://dx.doi.org/10.1016/j.jmatprotec.2013.11.025.

[8] R.Uday Kumar, "Analysis of Fukui's Conical Cup Test" International Journal of Innovative Technology and Exploring Engineering (IJITEE) ISSN: 2278-3075, Volume-2, Issue-2, January (2013).

[9] T. Trzepiecinski," 3D elasto-plastic FEM analysis of the sheet drawing of anisotropic steel sheet" Archives of Civil and Mechanical Engineering, Vol. X, No. 4, (2010).

[10] Anup S. Atal, M. T. Shete," Formability Analysis of Deep drawing Process by Finite Element Simulation " International Journal of Science and Research (IJSR), ISSN (Online): 2319-7064, Volume 3 Issue 6, June (2014). 